\title{
Comparison of the Prevalence of Antinuclear Antibody and Subserology in Urban and Rural Settings
}

\author{
Adrian Yong-Sing LEE, ${ }^{1}$ Leigh MURFETT, ${ }^{2}$ Udayan $\mathrm{RAY}^{3,4}$ \\ ${ }^{1}$ Department of Medicine, Western Health, Melbourne, Australia \\ ${ }^{2}$ Diagnostic Services Pty Ltd, Launceston, Australia \\ ${ }^{3}$ Department of Pathology, Royal Hobart Hospital, Hobart, Australia \\ ${ }^{4}$ University of Tasmania, School of Medicine, Hobart, Australia
}

Arguably one of the most commonly ordered autoantibody tests, the antinuclear antibody (ANA) test is frequently used in a variety of medical disciplines including rheumatology. ${ }^{1}$ ANA has become a general marker of autoimmunity in clinical practice and is measured in titres and fluorescent patterns.

Although previous studies have investigated the prevalence of ANA positivity in regional/ rural areas, ${ }^{2,3}$ very limited number of studies have directly compared ANA positivity in rural and urban areas. Hence, we decided to evaluate ANA and its subserologies [anti-extractable nuclear antigens (anti-ENA) and anti-double stranded deoxyribonucleic acid (anti-dsDNA)] in both an urban and rural population of Tasmania, Australia.

The study included a total of 32,600 firstepisode ANA tests with any concurrent antiENA and-dsDNA tests which were requested for urban and rural patients 10,577 males (32.4\%), 22,005 females (67.5\%); mean age 49.2 years; range 0 to 99 years) in the north-west rural district and southern urban district laboratories between January 2004 and December 2014. These included both general practice (community) and hospital requests. Duplicate testing were excluded. All ANA tests, performed on the HEp-2000 ${ }^{\circledR}$ substrate (Immuno Concepts Inc., Sacramento, CA, USA), were conducted by the same master laboratory and a positive result was deemed at a titre of $\geq 1: 80$. The HEp-2000 substrate is similar to the standard HEp-2 substrate but has Sjögren's syndrome A (Ro/SSA) complementary DNA transfected into it to create a unique 'SSA/speckled' pattern on immunofluorescence microscopy. AntiENA testing was performed by enzyme-linked immunosorbent assay (Immuno Concepts) and anti-dsDNA testing via EIA (Immuno Concepts) and Farr radioimmunoassay (Siemens Healthcare Diagnostics, Erlangen, Germany). Tests were extracted anonymously and ethics approval to conduct the investigation was granted by the Tasmanian Health and Medical Human Research Ethics Committee.

Approximately two-thirds of the tests originated from the urban center $(n=20,765$, 63.7\%). Though there was slightly higher ANA positivity from the rural center (Table 1), there were no differences when broken down according to patterns. There was, however, a trend for higher-titred ANA being more prevalent in rural areas. Finally, whilst there was no difference in 
Table 1. Comparison of antinuclear antibody and subserologies in an urban versus rural center

\begin{tabular}{|c|c|c|c|c|c|c|c|}
\hline & \multicolumn{3}{|c|}{ Urban center } & \multicolumn{3}{|c|}{ Rural center } & \multirow{2}{*}{$\begin{array}{c}\begin{array}{c}\text { Value for } \\
\text { differences in } \\
\text { proportions }\end{array} \\
p\end{array}$} \\
\hline & $\mathrm{n}$ & $\%$ & Mean \pm SD & $\mathrm{n}$ & $\%$ & Mean \pm SD & \\
\hline ANA cases & 20765 & & & 11835 & & & \\
\hline Females* & 14274 & 68.8 & & 7731 & 65.3 & & $<0.001$ \\
\hline Age (years) & & & $49.0 \pm 17.6$ & & & $49.4 \pm 18.1$ & 0.051 \\
\hline General practitioner requests & 3383 & 16.3 & & 1988 & 16.8 & & 0.242 \\
\hline Positive ANA cases & 4457 & 21.5 & & 2662 & 22.5 & & 0.036 \\
\hline \multicolumn{8}{|l|}{ ANA patterns: } \\
\hline Speckled & 1647 & 36.9 & & 937 & 35.2 & & 0.149 \\
\hline Homogeneous & 1294 & 29.0 & & 770 & 28.9 & & 0.928 \\
\hline Nucleolar & 99 & 2.2 & & 560 & 21.0 & & 0.362 \\
\hline Centromeric & 151 & 3.4 & & 57 & 2.1 & & 0.779 \\
\hline SSA pattern & 151 & 3.4 & & 115 & 4.3 & & 0.053 \\
\hline Mixed/miscellaneous & 369 & 8.3 & & 223 & 8.4 & & 0.883 \\
\hline \multicolumn{8}{|l|}{ ANA titres $\neq$} \\
\hline Low $(1: 80,1: 160)$ & 2516 & 57.2 & & 1416 & 54.0 & & 0.009 \\
\hline Medium (1:320, 1:640) & 1362 & 31.0 & & 857 & 32.7 & & 0.138 \\
\hline High $(>1: 1280)$ & 522 & 11.9 & & 350 & 13.3 & & 0.085 \\
\hline Anti-ENA requests (concurrent) & 3003 & 14.5 & & 1186 & 10.0 & & $<0.001$ \\
\hline Positive anti-ENA result & 139 & 4.6 & & 65 & 5.5 & & 0.222 \\
\hline Anti-dsDNA requests (concurrent) & 1275 & 6.1 & & 951 & 8.0 & & $<0.001$ \\
\hline Positive anti-dsDNA result & 84 & 6.6 & & 86 & 9.0 & & 0.035 \\
\hline
\end{tabular}

anti-ENA positivity, there was higher anti-dsDNA positivity in the rural center (Table 1).

Our results demonstrate that autoantibody positivity tends to be higher in rural areas compared to urban areas. This is in line with one study in a Polish rural community that demonstrated that ANA, anti-ENA, and -dsDNA are proportionally more positive compared to an urban area. ${ }^{4}$ Another study of systemic lupus erythematosus patients, however, found no significant difference in ANA and anti-dsDNA positivity between urban and rural patients. ${ }^{5}$

Our results are paradoxical given that epidemiological studies find decreased autoimmune diagnoses in regional areas. ${ }^{6,7}$ This indicates that autoantibodies may not be the best surrogate marker for autoimmunity and is congruent with the fact that autoantibodies may be raised in many non-autoimmune states including chronic inflammation. Unfortunately, the epidemiology of autoimmune conditions in Tasmania (Australia) is not available to correlate our results to. This information would be useful in understanding the relationship between autoimmune serology and epidemiology. Certainly, further epidemiological studies of autoimmunity would be of great benefit.

\section{Declaration of conflicting interests}

The authors declared no conflicts of interest with respect to the authorship and/or publication of this article.

\section{Funding}

The authors received no financial support for the research and/or authorship of this article.

\section{REFERENCES}

1. Mahler M, Meroni PL, Bossuyt X, Fritzler MJ. Current concepts and future directions for the assessment of autoantibodies to cellular antigens referred to as anti-nuclear antibodies. J Immunol Res 2014;2014:315179.

2. Roberts-Thomson PJ, Nikoloutsopoulos T, Cox S, Walker JG, Gordon TP. Antinuclear antibody testing in a regional immunopathology laboratory. Immunol Cell Biol 2003;81:409-12.

3. Rosenberg AM, Semchuk KM, McDuffie HH, Ledingham DL, Cordeiro DM, Cessna AJ, et al. Prevalence of antinuclear antibodies in a rural population. J Toxicol Environ Health A 1999;57:225-36.

4. Spiewak R, Stojek N. Antinuclear antibodies among eastern-Polish rural inhabitants. Ann Agric Environ Med 2003;10:207-9.

5. Pons-Estel GJ, Saurit V, Alarcón GS, Hachuel L, 
Boggio G, Wojdyla D, et al. The impact of rural residency on the expression and outcome of systemic lupus erythematosus: data from a multiethnic Latin American cohort. Lupus 2012;21:1397-404.

6. Shapira Y, Agmon-Levin N, Shoenfeld Y.
Geoepidemiology of autoimmune rheumatic diseases. Nat Rev Rheumatol 2010;6:468-76.

7. Tobón GJ, Youinou P, Saraux A. The environment, geo-epidemiology, and autoimmune disease: Rheumatoid arthritis. J Autoimmun 2010;35:10-4. 